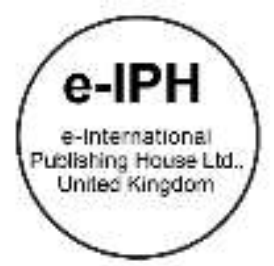

\title{
Medical Tourism from the Perspectives of Industry Players: How Critical is Government Support?
}

\author{
Herwina Rosnan ${ }^{1}$, Norzayana Yusof ${ }^{2}$ \\ ${ }^{1}$ Arshad Ayub Graduate Business School, Universiti Teknologi MARA, Shah Alam 40450, Malaysia \\ 2 Faculty of Business and Management, Universiti Teknologi MARA, Shah Alam 40450, Malaysia \\ herwina@uitm.edu.my,norzayana.yusof@gmail.com \\ Tel of 1 st Author: +60192345680
}

\begin{abstract}
The present study aims to derive the role of the government in developing Malaysian medical tourism. Nine semi-structured interviews were conducted and data were analysed thematically using Atlas.ti version 8 . The study derived four main challenges facing private hospitals and healthcare facilitators, which are regulatory burden, scarcity of health professionals, poor collaboration with state government and low cooperation from other agencies. These challenges then drew the government's role accordingly. Hence, this article strongly calls for regular dialogues between government agencies, private hospitals and healthcare facilitators to ensure that all stakeholders are on the same page about developing the industry.
\end{abstract}

Keywords: Medical Tourism, Private Hospitals, Healthcare Facilitators, Government

eISSN: 2398-4287@ 2021. The Authors. Published for AMER ABRA cE-Bs by e-International Publishing House, Ltd., UK. This is an open access article under the CC BYNC-ND license (http://creativecommons.org/licenses/by-nc-nd/4.0/). Peer-review under responsibility of AMER (Association of Malaysian Environment-Behaviour Researchers), ABRA (Association of Behavioural Researchers on Asians/Africans/Arabians) and cE-Bs (Centre for Environment-Behaviour Studies), Faculty of Architecture, Planning \& Surveying, Universiti Teknologi MARA, Malaysia.

DOI: https://doi.org/10.21834/ebpj.v6iSI4.2912

\subsection{Introduction}

Medical tourism in Malaysia is the result of the 1997 Asian economic crisis. Hospitals were suffering from dwindling number of patients due to financial crises that affected their purchasing power. The sharp fall of hospital revenues leads to the work of attracting foreign patience. This resulted in the establishment of the Medical and Health Tourism Committee (MHTC) in 2005 under the Ministry of Health, which functions as a national committee to promote medical tourism. Today, under the Ministry of Finance, MHTC continues to facilitate and promote the medical tourism industry by coordinating industry collaborations to be the leading provider of quality healthcare globally (Malaysia Healthcare Travel Council, 2019a).

Wong and Musa (2012) suggested that the strong factors driving medical tourism in Malaysia include attractive medical services cost, less waiting time, political stability, minimal language barrier and various tourism attractions. Additionally, Malaysia's multiculturalism has been reputed as one of the preferred medical tourism destinations by major countries in Asia (Ormond, 2010; cited in Rokni, Turgay \& Park, 2017). Other researchers found similar factors, namely good infrastructure (Momeni, Janati, Imani, \& KhodayariZarnaq, 2018), strong government support, and ease of communication (Heung, Kucukusta, \& Song, 2011; Ngamvichaikit \& Beise-Zee, 2014; Rokni et al., 2017).

In 2018, Malaysia received 1.2 million health tourists with a revenue of RM 1.5 billion. This is a steadying increase from 643,000 health tourists with MYR527 million in 2011 (Malaysia Healthcare Travel Council, 2019b). Despite the positive outlook, 'Medical' expenditure only takes up 3.7\% from the Total Foreign Tourists Expenditure in Malaysia for 2017 without much improvements from

eISSN: 2398-4287C 2021. The Authors. Published for AMER ABRA cE-Bs by e-International Publishing House, Ltd., UK. This is an open access article under the CC BYNC-ND license (http://creativecommons.org/licenses/by-nc-nd/4.0/). Peer-review under responsibility of AMER (Association of Malaysian Environment-Behaviour Researchers), ABRA (Association of Behavioural Researchers on Asians/Africans/Arabians) and cE-Bs (Centre for Environment-Behaviour Studies), Faculty of Architecture, Planning \& Surveying, Universiti Teknologi MARA, Malaysia.

DOI: https://doi.org/10.21834/ebpj.v6iSI4.2912 
2016 (3.6\%) and 2015 (3.1\%) (Tourism Malaysia, 2017a, 2017b, 2019). This issue occurred due to the high utilisation of low- value services such as health screenings which generate low average revenue per patient (National Transformation Program, 2017). Thus, it can be argued that the positive inflow of health tourists is not translated into the actual medical revenues that the industry is generating. Although MHTC announced their strategy of focusing on high-value treatments consisting of cardiology and fertility, such an approach would require numerous supports from the government, especially through public-private partnerships (PPP).

This article aims at delineating the role of the government is offering support for medical tourism. It is crucial to note that this article was produced as part of a more significant project on medical tourism. Hence, the participants are limited to private hospitals and healthcare facilitators that involve in medical tourism. A qualitative exploratory study was conducted to attain an understanding of the service providers' expectations on the role of government. Hence, this study is among the first few that offer insights into the meanings of government support as explained by the industry players.

\subsection{Literature Review}

Medical tourism is a subset of health tourism, and the latter is a subset of tourism studies (de la Hoz-Correa, Muñoz-Leiva, \& Bakucz, 2018) as hospitals' core business is offering healthcare services, venturing into medical tourism as a means of diversifying revenue sources. Extant literature mainly discussed the barriers to developing the medical tourism industry, which is mainly on policies and regulations, culture and language (Heung et al., 2011; Rokni et al., 2017). Moreover, Momeni et al. (2018) revealed several inductive findings, including transferring patients to and fro their destination country.

In Malaysia, most studies have been done on medical tourists' perspectives. This includes their intention to choosing Malaysia (Seow, Choong, Moorthy, \& Chan, 2017), patient satisfaction (Musa, Doshi, Wong, \& Thirumoorthy, 2012) and future intention for treatments (Manaf, Hussin, Kassim, Alavi, \& Dahari, 2015). A study by Rosnan, Yusof and Shamsuddin (2019) found that Thailand is a leading destination for medical tourism relative to other ASEAN countries. Nevertheless, there is a lack of studies conducted to attain first-hand perspectives on the role of industry players to develop the industry.

As Medhekar (2019) and Skountridaki (2017) explained on the communication barriers and the roles of healthcare facilitators, focus on the government's support should receive equal attention. There is limited empirical evidence from the perspectives of hospitals and healthcare facilitators toward the government pertaining to developing the industry. This is due to the extensive focus on the demand side, such as patients decision-making process (Shahrokh, Brojeni, Nasehifar, \& Kamalabadi, 2017) and push-and-pull factors (de la Hoz-Correa et al., 2018).

As for this study, two main players were identified, namely private hospitals and healthcare facilitators that were directly involved in the provision and facilitation of healthcare services. Consequently, the study is expected to highlight the barriers that may hinder the success of the industry. This is followed by deriving the expectations of the service providers towards the government. Therefore, the present study fills the gap in the literature and contributes empirical evidence of the current status of medical tourism in Malaysia. This is done by providing the current status of the supply-side of the industry from the private hospitals and healthcare facilitators' perspectives.

\subsection{Methodology}

This paper aims at exploring the perceptions of private hospitals and health facilitators on the role of government in developing medical tourism. Hence, data collection was conducted from Phase 1 to Phase 2 until the next participant did not express new knowledge about the industry that has been mentioned by the former. It is important to note that this article is part of a larger project. Hence, the decision to end the data collection was based on the actual research work.

Data collection is divided into two phases, namely direct observation (Phase 1) and semi-structured interviews (Phase 2). Phase 1 was conducted during the InsigHT2018 Medical Travel Market Intelligence Conference by MHTC in September 2018. This conference is coded as $\mathrm{C} 01$. Meanwhile, another direct observation was carried out in a workshop by a government agency in October of the same year, which is coded as W01. Due to confidentiality, the workshop details would not be revealed. This phase is crucial to attaining current issues revolving around medical tourism and private healthcare. It helped in narrowing the questions for the upcoming semi-structured interviews. Secondary data through the PowerPoint slides in $\mathrm{C} 01$ were taken to assist in the triangulation process. Hence, this data is coded as Note1 and Note2. The researchers built rapport with the private hospitals and healthcare facilitators during the two events. It was later that the researchers began requesting to conduct semi-structured interviews.

Therefore, Phase 2 of the data collection consists of nine semi-structured interviews consisting of seven private hospitals and two healthcare facilitators. The hospitals are labelled as Private Hospital 1 (PH1), PH2 ...and PH7. The seven hospitals were interviewed between December 2018 and April 2019. They are scattered in Penang, Kuala Lumpur, Selangor and Johor. Meanwhile, the two healthcare facilitators consist of Healthcare Facilitator 1 (HF1) and MHTC Concierge \& Lounge (MCL). HF1 is an Indonesian-based company that brings medical tourists into Malaysia. MCL is a service operator that is located in Penang International Airport and Kuala Lumpur International Airport (KLIA). To ensure anonymity, the exact location of $M C L$ is not revealed. An online interview was held with HF1 due to geographical constrain, while MCL went through a face-to-face interview just like the private hospitals. Each interview lasted for approximately one hour at the participants 'office. Data were then transcribed and analysed with Atlas.ti version 8 that assisted in coding and building themes. The list of private hospitals was derived from the MHTC website. The participants were reverted with a summary of the interview session to obtain their feedback. This step is crucial to ensure the validity of the data. Hence, the majority of the participants replied with their agreement with the summary, while some others returned with minor amendments about the content. 
Another step of strengthening the information validity was through data triangulation from Note1,Note2 and several annual reports by the relevant ministries. Accordingly, Table 1 illustrated the cross-tabulation of data across various sources. Moreover method triangulation through direct observation and semi-structured interviews assisted in determining the strengths of the data collected.

\subsection{Findings and Discussion}

Based on Table 1 below, concerns on government support were mentioned numerous times in Phase 1 and 2 of the data collection. Merriam and Tisdell (2015) contended that qualitative studies do not focus on the quantification of the codes, as it should not be the sole justification to inductively emerge a theme. Nevertheless, the relatively high mention about what the government could do to improve the situations in this industry opens the door for the emergence of a specific theme called 'the role of the government'. Hence, the present section offers an insight into the challenges faced by private hospitals and healthcare facilitators, thus deriving their expectations on the government.

Table 1: A theme 'Role of Government' was inducted from the findings



\subsection{Challenges to Develop Medical Tourism}

Factors that posed challenges include regulatory burden, scarcity of health professionals, and collaborations with different stakeholders. Therefore, the role of the government is delineated according to the specific challenges faced by the industry players. These factors are further elaborated in the following sections.

\subsubsection{Regulatory burden}

Despite the initiatives taken by the government to support local medical tourism, hospitals expressed grief from the regulatory burden. First, private hospitals lamented they are burdened with paperwork and documents to renew hospital licenses which need to be done every five years (previously every two years). The preparation of the document would take six months to be completed. This administrative process is at the expense of other activities, which affects the hospital productivity. Second, the bureaucracies in which hospitals have to respond to the Federal and State offices of the Private Medical Practice Control Section (PMPCS). This resulted in work redundancy which affects their efficiency. Moreover, bureaucracies and miscommunications also occur with other stakeholders such as the Local Authority and the Fire and Rescue Department, which delays the application process.

Third, in order to apply for an operation license, one of the criteria that must be met is the number of staff employed, which include doctors and nurses. However, private hospitals are currently facing high staff turnover. This condition affects the validity of private hospital licenses, in which hospitals have to re-apply and detail out the current staff underemployment. The participants saw that if the government can formulate a better mechanism to deal with the validity of private hospital licenses as a result of staff turnover, it would lessen the hospital's administrative burden.

The regulatory burden is found to cause direct and indirect barriers to the development of medical tourism (Rokni et al., 2017). Heung et al. (2011) were among the first few scholars that explored such barriers in Hong Kong, and they contended that policies and regulations are burdening in terms of medical practices and ethics, land scarcity and insufficient hospital capacity. Moreover, South Korean medical tourism is hampered by policies and regulations on promotion, as well as a training opportunities and industry competitiveness (Rokni et al., 2017). Meanwhile, Momeni et al. (2018) derived that a similar barrier descends through policy-making, planning and execution. Specifically, it occurs through limited advocacy, inadequate financial incentives and outdated laws.

\subsubsection{Scarcity of health professionals}

Both public and private healthcare are burdened with the scarcity of specialists and nurses, which have hampered the growth of the medical tourism industry. During the observation at W01, private hospitals suggested that medical doctors are given the liberty to serve in private hospitals after completing their Masters. As for nurses, private hospitals suggested more post-basic training opportunities as a means to ease their entry requirements to the workforce. Moreover, the participants also recommended the means to facilitate the accreditation process for the nursing syllabus by the Malaysian Qualification Agency (MQA). Nevertheless, a detailed explanation of the suggestions could not be enclosed due to the confidentiality of the information. 
Past studies have also derived on workforce scarcity in the medical tourism industry (Heung et al., 2011; Rokni et al., 2017). Nevertheless, the present study is novel in contributing to the causes of such a problem. In fact, to the best of the researchers' knowledge the present study is among the first few in Malaysia to explicate the underpinning workforce issues and develop suggested solutions that were proposed by the industry players themselves.

\subsubsection{Collaboration with State Government}

Some of the private hospitals highlighted that they receive little cooperation from the State Tourism, while some others mentioned the opposite. The former claim was made by the 'infant' hospitals that have only ventured in this industry for two years and below. Accordingly, the presence of local State Tourism is mainly at meetings and not in promotional activities such as trade shows, health talks, workshops, and networking sessions. Moreover, participants believe that State Tourism, through their expertise in the sector, could assist to further promote Malaysia as a preferred medical tourism destination.

Similarly, the State Government is expected to participate in the outreach programmes as it would instil more confidence in patients when seeing their presence. Had the agencies built the bond between them, cooperation and communication could be escalated. Consequently, this will contribute to enhancing the patients' experience throughout their trip. Therefore, it is important for the government through the Ministry of Health and Ministry of Tourism and Culture to have effective communication that leads to complementing each other's agencies' efforts.

\subsubsection{Cooperation from other Agencies}

Essential support by the Malaysian government is when the Immigration Department launched the eVisa (medical) to facilitate healthcare travel to Malaysia (Medical Tourism Malaysia, 2018). Despite the concerting effort, private hospitals lamented that medical tourists faced difficulties in dealing with the Immigration Department. Patients complained that they were not well treated at the country's entry points. As medical tourists are from neighbouring countries with various backgrounds, the perception towards foreign workers' influx into the country might be the reason for a less friendly treatment received.

Hence, it is important for the government to look into this matter and educate the front-liner in the Immigration Department to escalate their service quality and brand image. As reiterated by Kim, Holland, and Han (2013), a destination country's brand image and service quality strongly contribute to tourists' satisfaction and loyalty. In view of this, Thailand is leading in medical tourism as they treat foreign patients like a 'king' and provide top-notch services (Rosnan et al., 2019).

As reported by Wong et al. (2014), logistics were made easy for foreign medical tourists where the Commercial Vehicle Licensing Board issued permits that allow the hospital to ferry their customers and patients to commute to and fro airports to hospitals and hotels. However, the present study unveiled that those permits are meant for common vehicles. The interview participants claimed that hospitals are not allowed to transport patients using luxury commercial vehicles such as Toyota Alphard and other Multi-purpose Vehicles (MPVs). When hospitals are keen to offer premium services to medical tourists, this intention is hampered by restrictions from the Malaysia Road Transport Department. Hence, it is seen that a lack of understanding of the nature of medical tourism might be the reason for the poor cooperation between private hospitals and the mentioned agencies.

\subsection{Recommendations}

The government is hoped to improve on the dissemination of information across the medical tourism supply chain. Accordingly, information on the need for premium transportation and services at the immigration counter is essential for the comfort of medical tourists. As a means to escalate the communication, this study suggests regular dialogue sessions between the stakeholders so they would be on the same page about developing the medical tourism industry. Thus, policy amendment would follow suit, providing sensible guidelines for the industry players to refer to.

Table 3: Summary of the role of government with the relevant stakeholders

\begin{tabular}{|c|c|c|}
\hline Challenges & Role of the government & Relevant stakeholders \\
\hline $\begin{array}{l}\text { Regulatory } \\
\text { burden }\end{array}$ & $\begin{array}{l}\text { i. Streamlining the licensing application process across various } \\
\text { stages and agencies } \\
\text { ii. Improve the communication between government and private } \\
\text { service providers through regular dialogue }\end{array}$ & $\begin{array}{ll}\text { i. } & \text { Ministry of Health (CKAPS) } \\
\text { ii. } & \text { Ministry of Home Affairs (Fire and Rescue Department) } \\
\text { iii. } & \text { The local authority (City Hall/ City or Municipal Council) }\end{array}$ \\
\hline $\begin{array}{l}\text { Scarcity of } \\
\text { health } \\
\text { professionals }\end{array}$ & $\begin{array}{ll}\text { i. } & \text { Offer more training seats for nurses and specialists } \\
\text { ii. Amend the nursing syllabus for nurses } \\
\text { iii. To ease the serving requirements for specialists after graduation } \\
\text { iv. Relook at the nursing syllabus }\end{array}$ & $\begin{array}{ll}\text { i. } & \text { Ministry of Health } \\
\text { ii. } & \text { Ministry of Education (MQA) } \\
\text { iii. } & \text { Ministry of Human Resources } \\
\text { iv. } & \text { Malaysian Medical Council } \\
\text { v. } & \text { Nursing Board (MQA) }\end{array}$ \\
\hline $\begin{array}{l}\text { Collaboration } \\
\text { with State } \\
\text { Government }\end{array}$ & $\begin{array}{l}\text { i. State Government to participate more in marketing activities to } \\
\text { enhance potential medical tourists' confidence. }\end{array}$ & $\begin{array}{ll}\text { i. } & \text { State Government } \\
\text { ii. } & \text { Ministry of Tourism and Culture (State Tourism) } \\
\text { iii. } & \text { Ministry of Health }\end{array}$ \\
\hline $\begin{array}{l}\text { Cooperation } \\
\text { from other } \\
\text { agencies }\end{array}$ & $\begin{array}{l}\text { i. To ensure that relevant parties are on the same page with medical } \\
\text { tourism in terms of offering premium services for medical tourists. }\end{array}$ & $\begin{array}{l}\text { i. Ministry of Home Affairs (Immigration Department) } \\
\text { ii. } \quad \text { Ministry of Transport (Malaysian Road and Transport } \\
\text { Department) }\end{array}$ \\
\hline
\end{tabular}

\subsection{Conclusion \& Recommendations}

This study explored the expectation of private hospitals and healthcare facilitators towards the government as they face challenges in 
running the industry. Several issues that require government intervention have been addressed, and references were made to existing literature. This study supports extant literature that the role of government is crucial for the development of the medical tourism industry. Moreover, findings have unveiled that frequent dialogues between the relevant ministries, government agencies and private service providers are second to none in assisting the development of sensible guidelines and policies. Therefore, this study provides empirical evidence on the current development of medical tourism in Malaysia.

As with all research, this study is not free from limitations. The first constraint is being a part of a bigger research project. Once the actual project has reached saturation, it marks the end of the data collection process. This situation explains the small number of participants in this article. The second limitation is the small variety of stakeholders, being only private hospitals and healthcare facilitators. The absence of the Tourism Board and MHTC hampers the richness of the data had their views were incorporated. Finally, the nature of the study as cross-sectional barricades the understanding of a trend of behaviour among the stakeholders over time. Therefore, future studies are suggested to integrate other stakeholders such as insurance companies and government agencies. $\mathrm{A}$ similar qualitative study could be conducted at inter-and intra-state levels as Klijs, Ormond, Mainil, Peerlings, and Heijman (2016) conjectured that each state in Malaysia has their distinctive ways of running and earning from medical tourism.

\section{Acknowledgements}

The authors gratefully acknowledge the help of the Research Management Centre, Institute of Research \& Innovation (IRMI), Universiti Teknologi MARA, Shah Alam for the support in managing the grant and to AAGBS for financial support through AAGBS Grant. File No: 600-IRMI/DANA 5/3/AAGBS (006/2018).

\section{References}

de la Hoz-Correa, A., Muñoz-Leiva, F., \& Bakucz, M. (2018). Past themes and future trends in medical tourism research: A co-word analysis. Tourism Management, 65, 200-211. doi:10.1016/j.tourman.2017.10.001

Heung, V. C. S., Kucukusta, D., \& Song, H. (2011). Medical tourism development in Hong Kong: An assessment of the barriers. Tourism Management, 32(5), 995-1005. doi:https://doi.org/10.1016/j.tourman.2010.08.012

Kim, S.-H., Holland, S., \& Han, H.-S. (2013). A Structural Model for Examining how Destination Image, Perceived Value, and Service Quality Affect Destination Loyalty: a Case Study of Orlando. International Journal of Tourism Research, 15(4), 313-328. doi:10.1002/jtr.1877

Klijs, J., Ormond, M., Mainil, T., Peerlings, J., \& Heijman, W. (2016). A state-level analysis of the economic impacts of medical tourism in Malaysia. Asian-Pacific Economic Literature, 30(1), 3-29.

Malaysia Healthcare Travel Council. (2019a). Who We Are. Retrieved from https://www.mhtc.org.my/discover-mhtc/\#who

Malaysia Healthcare Travel Council. (2019b). Number of Healthcare Travellers and Revenue between 2011-2018. Retrieved from https://www.mhtc.org.my/

Manaf, N. H. A., Hussin, H., Kassim, P. N. J., Alavi, R., \& Dahari, Z. (2015). Medical tourism service quality: finally some empirical findings. Total Quality Management \& Business Excellence, 26(9/10), 1017-1028. doi:10.1080/14783363.2015.1068597

Medhekar, A. (2019). Role, Rules, and Regulations for Global Medical Tourism Facilitators. In D. Mohinder Chand \& C. Vinay (Eds.), Handbook of Research on International Travel Agency and Tour Operation Management (pp. 81-100). Hershey, PA, USA: IGI Global.

Medical Tourism Malaysia. (2018). Healthcare Travel Made Easy with eVISA (Medical). Retrieved from https://medicaltourismmalaysia.com/our-services/evisa/

Merriam, S. B., \& Tisdell, E. J. (2015). Qualitative research: A guide to design and implementation. United States of America: Jossey-Bass.

Momeni, K., Janati, A., Imani, A., \& Khodayari-Zarnaq, R. (2018). Barriers to the development of medical tourism in East Azerbaijan province, Iran: A qualitative study Tourism Management, 69, 307-316.

Musa, G., Doshi, D. R., Wong, K. M., \& Thirumoorthy, T. (2012). How Satisfied are Inbound Medical Tourists in Malaysia? A Study on Private Hospitals in Kuala Lumpur. Journal of Travel \& Tourism Marketing, 29(7), 629-646. doi:10.1080/10548408.2012.720150

National Transformation Program. (2017). Economic Transformation Program Annual Report 2016.

Ngamvichaikit, A., \& Beise-Zee, R. (2014). Communication needs of medical tourists: An exploratory study in Thailand. International Journal of Pharmaceutical and Healthcare Marketing, 8(1), 98-117. doi:10.1108/JJPHM-10-2012-0010

Rokni, L., Turgay, A., \& Park, S. H. (2017). Barriers of developing medical tourism in a destination: A case of South Korea. Iran J Public Health, 46(7), 930.

Rosnan, H., Yusof, N., \& Shamsuddin, S. (2019). Service Culture of the Workforce in the Medical Tourism Industry: is Malaysia on Par With Thailand? EnvironmentBehaviour Proceedings Journal, 4(11).

Seow, A. N., Choong, Y. O., Moorthy, K., \& Chan, L. M. (2017). Intention to visit Malaysia for medical tourism using the antecedents of Theory of Planned Behaviour: A predictive model. The International Journal of Tourism Research, 19(3), 383-393. doi:http://dx.doi.org/10.1002/jtr.2120 
Shahrokh, Z. D., Brojeni, H. Z., Nasehifar, V., \& Kamalabadi, H. N. (2017). A progressive multilevel model for selecting medical tourism destinations: a qualitative study. International Journal of Travel Medicine and Global Health, 5(2), 60-68.

Skountridaki, L. (2017). Barriers to business relations between medical tourism facilitators and medical professionals. Tourism Management, 59, 254-266.

Tourism Malaysia. (2017a). Annual Report 2015: Malaysia Tourism Promotion Board, Ministry of Tourism, Arts \& Culture. Retrieved from https://www.tourism.gov.my/activities/view/tourism-malaysia-2015-annual-report

Tourism Malaysia. (2017b). Annual Report 2016: Malaysia Tourism Promotion Board, Ministry of Tourism, Arts \& Culture. Retrieved from https://www.tourism.gov.my/activities/view/tourism-malaysia-2016-annual-report

Tourism Malaysia. (2019). Annual Report 2017: Malaysia Tourism Promotion Board, Ministry of Tourism, Arts \& Culture. Retrieved from https://www.tourism.gov.my/activities/view/tourism-malaysia-2015-annual-report

Wong, K. M., \& Musa, G. (2012). Medical tourism in Asia: Thailand, Singapore, Malaysia, and India. Medical tourism: the ethics, regulation, and marketing of health mobility. London and New York: Routledge, 167 Á186.

Wong, K. M., Velasamy, P., \& Arshad, T. N. T. (2014). Medical tourism destination SWOT analysis: A case study of Malaysia, Thailand, Singapore and India. Paper presented at the SHS Web of Conferences. 